\title{
Glycogen Synthase Kinase-3 Regulates Mouse Oocyte Homologue Segregation
}

\author{
XIA WANG,${ }^{1,3,4}$ XIAO-TIE LIU, ${ }^{1}$ RODNEY DUNN, ${ }^{3}$ DANA A. OHL, ${ }^{3}$ AND GARY D. SMITH ${ }^{1,2,3,4 *}$ \\ ${ }^{1}$ Department of Obstetrics and Gynecology, University of Michigan, Ann Arbor, Michigan \\ ${ }^{2}$ Department of Physiology, University of Michigan, Ann Arbor, Michigan \\ ${ }^{3}$ Department of Urology, University of Michigan, Ann Arbor, Michigan \\ ${ }^{4}$ Reproductive Sciences Program, University of Michigan, Ann Arbor, Michigan
}

\begin{abstract}
Intracellular regulation of oocyte meiosis is not completely understood. However, reversible phosphorylation, which involves serine/ threonine protein kinases and phosphatases (PP), is an important mediator. Glycogen synthase kinase-3 (GSK-3) is a highly conserved serine/threonine protein kinase. Currently no reports exist on presence or function of GSK-3 in mammalian oocytes. The aim of this study was to determine GSK-3 presence/absence, transcript and protein expression, intracellular protein distribution, and to investigate the functional importance of GSK-3 in mouse oocyte meiosis. Germinal vesicle-intact (GVI) oocytes contained both GSK-3 transcript and protein. Although GSK-3 $\beta$-isoform is the only transcript identifiable in GVI oocytes, both $\alpha$ - and $\beta$-isoforms were recognized by Western blot analysis. In growing, meiotic-incompetent oocytes GSK-3 was present, diffusely located throughout the cytoplasm and absent in the nucleus, whereas in meiotic-competent oocytes this cytoplasmic GSK-3 displays a predominant peri-oolemma staining. Treatment of mouse GVI oocytes with lithium chloride ( $\mathrm{LiCl}$ ), which inhibits both inositol monophosphatase (IMPase) and GSK-3, had no significant influence on oocyte viability, morphology, or development to metaphase II (MII). However, LiCl caused abnormal spindle formation and significantly increased incidence of abnormal homologue segregation during the first meiotic division. L690,330, which is a specific IMPase inhibitor, had no significant effect on oocyte viability, morphology, MII development, or homologue segregation. This is the first report of GSK-3 in mammalian oocytes. LiCl inhibition of mouse oocyte GSK-3 modified organization of microtubules and/or function of meiotic spindles thus compromising segregation of condensed bivalent chromosomes. Mol. Reprod. Dev. 64: 96-105, 2003. @ 2003 Wiley-Liss, Inc.
\end{abstract}

Key Words: glycogen synthase kinase-3; lithium chloride; maturation; chromatin; oocyte; mouse

\section{INTRODUCTION}

Important events occurring during oocyte meiotic maturation are germinal vesicle breakdown (GVBD), condensation of chromatin, alignment of bivalents on spindles at metaphase I (MI), and separation and segregation of homologues during anaphase and telophase I. This nuclear maturation process is considered complete following bivalent chromatin separation in conjunction with disproportionate cytokinesis, extrusion of the first polar body and meiotic arrest at metaphase II (MII). While the importance of kinases and phosphatases, and thus reversible phosphorylation, in regulation of meiosis is well appreciated the actual enzymes and their intracellular roles in controlling meiotic progression are incompletely understood.

Lithium chloride ( $\mathrm{LiCl}$ ) has been used to study intracellular regulation of mouse oocyte meiosis with contradictory outcomes. Initially $\mathrm{LiCl}$ was shown to stimulate GVBD in oocytes treated with the meiotic-blocking agent forskolin, but not in the presence of dibutyrylcAMP (dbcAMP; Gavin and Schorderet-Slatkine, 1988). Conversely, $\mathrm{LiCl}$ was found to stimulate both GVBD and polar body formation in the presence of dbcAMP (Bagger et al., 1993). Pesty et al. (1994) reported that LiCl inhibits both GVBD and MII development in spontaneously matured oocytes. Lastly, $\mathrm{LiCl}$ was found to have no effect on oocyte spontaneous, but inhibited hormonal- and growth factor-stimulated, resumption of meiosis (Coticchio and Fleming, 1998). There are two primary mechanisms of action to account for LiCl's cellular effects. First, $\mathrm{LiCl}$ can inhibit inositol monophosphatase (IMPase), which results in depletion of endogenous inositol thus preventing formation of inositol triphosphate $\left(\mathrm{IP}_{3}\right.$; Hallcher and Sherman, 1980; Berridge et al., 1989). Second, $\mathrm{LiCl}$ can inhibit both isoforms of glycogen synthase kinase-3 (GSK-3) (Klein and Melton, 1996; Stambolic et al., 1996). Past studies on LiCl's effects on oocyte maturation have focused on the role of polyphosphoinositide metabolism without consideration of the GSK-3 pathway.

Grant sponsor: NIH; Grant number: HD35125-01A1.

Xiao-Tie Liu's present address is Department of Pediatrics/Division of Neonatal-Perinatal Medicine, UT Southwestern Med CTT, 5323 Harry Hine Blvd., Dallas, TX 75235-7216.

*Correspondence to: Dr. Gary D. Smith, 6428 Medical Sciences Building I. 1301 E. Catherine St., Ann Arbor, MI 48109-0617.

E-mail: smithgd@umich.edu

Received 15 April 2002; Accepted 22 July 2002

Published online in Wiley InterScience (www.interscience.wiley.com). DOI: $10.1002 / \mathrm{mrd} .10213$ 
GSK-3 is a highly conserved serine/threonine protein kinase that was initially discovered as one of many kinases that phosphorylate and inactivate glycogen synthase, the rate-limiting enzyme in glycogen synthesis (Embi et al., 1980; Rylatt et al., 1980; Hemmings et al., 1982). GSK-3 is active in resting cells and is primarily regulated by inactivation in response to signal transduction pathways originating from various growth factors (Cook et al., 1996). Molecular cloning revealed existence of two highly related proteins termed GSK- $3 \alpha$ and GSK-3 $\beta$ with molecular masses of 51 and $46 \mathrm{kDa}$, respectively (Woodgett, 1990; Hughes et al., 1992). While GSK-3 function has been well studied in neuronal (review see: Phiel and Klein, 2001) and somatic cells (review see: Sakanaka et al., 2000) its presence and/or role in mammalian gametes is limited to studies in spermatozoa (Smith et al., 1996; Smith et al., 1999; Vijayaraghavan et al., 2000).

GSK-3 is involved in a wide range of cellular processes beyond regulation of glycogen synthases. For instance, GSK-3 phosphorylates the inhibitory subunit I2 of the protein phosphatase-1 (PP1)-I2 complex thus activating PP1 (VandenHeede et al., 1980; Hemmings et al., 1981). GSK-3 can interrupt the Wnt/ $\beta$-catenin transduction pathway by destabilizing $\beta$-catenin and thus blocking $\beta$-catenin-induced transcription (Sakanaka et al., 2000), as well as regulate transcription through transcription factors such as c-jun, c-myc, and CREB (Boyle et al., 1991; Plyte et al., 1992; Fiol et al., 1994). In addition, GSK-3 can regulate phosphorylation of numerous microtubule associated proteins subsequently influencing microtubule polymerization and stability, spindle formation, and function (Stambolic et al., 1996; Moreno and Avila, 1998; Lovestone et al., 1999; Sanchez et al., 1999). Interestingly, it has been reported that $\mathrm{LiCl}$ treatment of mouse oocytes causes important changes in meiotic spindle configuration and function, as well as chromatin organization (Pesty et al., 1994). However, it has not been determined whether this $\mathrm{LiCl}$ effect is through inhibition of IMPase or GSK-3.

The objective of the first portion of this study was to determine GSK-3 presence/absence within mouse oocytes, characterize GSK-3 transcript and protein expression, and elucidate the intracellular GSK-3 distribution during oocyte growth and acquisition of meiotic competence. Secondly, experiments were performed to evaluate influences of the GSK-3/IMPase inhibitor, $\mathrm{LiCl}$, and the specific IMPase inhibitor, L690,330 (Atack et al., 1993; Klein and Melton, 1996), on mouse oocyte viability, spontaneous meiotic resumption, and progression, microtubule polymerization and spindle formation, and homologue segregation.

\section{MATERIALS AND METHODS Collection of Ovarian Tissue, Oocytes, and Oocyte Culture}

Ovaries were obtained from CF-1 mice on day 11 or 15 (day $0=$ day of birth) without hormonal stimulation or from 19- to 23-day-old mice primed with 10 IU equine chorionic gonadotropin (eCG, Sigma Chemical Co., Louis, MO). Fully-grown GVBD-competent oocytes were isolated by manual rupturing of antral ovarian follicles. Oocytes were isolated into modified Human Tubal Fluid media $+0.3 \%$ (wt/vol) polyvinylpyrrolidone (HTFH + PVP; Quinn et al., 1985; Irvine Scientific, Santa Ana, CA) for transcript and protein studies or $\mathrm{HTFH}+0.3 \%$ (wt/vol) bovine serum albumin (BSA, Fisher Scientific, Fair Lawn, NJ) for culture experiments. For reverse transcription-polymerase chain reaction (RT-PCR) and Western blot analysis germinal vesicle-intact (GVI) oocytes were completely freed of attached cumulus cells in HTFH + PVP by manual pipetting with a hand-pulled borosilicate pipette. Cumulus-free fully-grown GVI oocytes were frozen in liquid nitrogen and stored at $-80^{\circ} \mathrm{C}$ until RNA and protein extracts were prepared. For immunohistochemical studies, ovaries were fixed in $4 \%$ (wt/vol) paraformaldehyde (prepared fresh daily), rinsed in PBS, and embedded in paraffin.

For culture experiments, GVBD-competent oocytes and accompanying cumulus cells were placed in HTF containing $0.3 \%$ BSA alone or containing potassium chloride (KCl), LiCl, or L690,330 (Tocris, Ballwin, MO). Following $16 \mathrm{hr}$ incubation at $37^{\circ} \mathrm{C}$ with $5 \% \mathrm{CO}_{2}$ in air, cumulus cells were removed by manual pipetting and viability, morphology, and stage of meiotic development were assessed with an inverted microscope using Hoffman optics at $400 \times$. In some experiments, resulting MII oocytes were used for immunocytochemical analysis for normal microtubule polymerization/spindle formation. In addition, MII oocytes in vitro-matured in HTF alone (control; $\mathrm{n}=56)$, or containing $20 \mathrm{mM} \mathrm{KCL}(\mathrm{n}=65)$, $20 \mathrm{mM} \mathrm{LiCl}(\mathrm{n}=79), 20 \mu \mathrm{M}$ L690,330 $(\mathrm{n}=60)$ were stained with $5 \mu \mathrm{g} / \mathrm{ml}$ Hoechst 3342 , mounted by $90 \%$ (vol/vol) glycerol in PBS, and chromatin was visualized with conventional fluorescence microscopy at $1,000 \times$. Oocytes were evaluated, in a treatment-blinded fashion, for normal homologue segregation. Effect of treatment on percentage of MII oocytes with abnormal homologue segregation was statistically analyzed with Fisher's Exact Test. Differences were considered significant with $P<0.05$.

\section{Oocyte RNA Isolation and RT-PCR}

Eighty to one hundred oocytes were thawed in $20.0 \mathrm{IU}$ RNasin (Promega, Madison, WI), pooled and lysed with 5 freeze/thaw cycles in liquid nitrogen. Total RNA was isolated as previously described (Heikinheimo et al., 1995; Smith et al., 1998). Complementary DNA was synthesized using the "Superscript Preamplification System for First Strand cDNA Synthesis" reagents and methodology (Gibco BRL, Gaithersburg, MD). Oligo-dT was used to prime reverse transcription reactions. In the case of GSK- $3 \alpha$, both oligo-dT and a gene specific primer (GSP) were used.

For GSK- $3 \alpha$ and GSK-3 $\beta$ PCR sense and antisense primers were designed from areas with least homology to amplify size-discernible products with distinct 
restriction endonuclease digestion sites (Table 1). Each PCR was performed with five oocyte equivalents of cDNA, 20 pmoles of each primer, and PCR cocktail [0.4 mM of each dNTP, $2.0 \mathrm{mM} \mathrm{MgCl}_{2}, 10.0 \mathrm{mM}$ Tris$\mathrm{HCl}(\mathrm{pH}$ 8.3), $50.0 \mathrm{mM} \mathrm{KCl}$, and 2.0 I.U. of Taq DNA polymerase (Perkin-Elmer, Foster City, CA)]. In addition, control reactions were conducted consisting of (1) no template with primers and cocktail; (2) no primers with cDNA template and cocktail; (3) no template or primer with cocktail, and (4) total RNA as template (equivalent to five oocytes) with primers and cocktail. Total RNA controls were only performed if amplification signals were previously identified in oocytes. Polymerase chain reactions entailed 1 cycle for $2 \mathrm{~min}$ at $94^{\circ} \mathrm{C}$; 35 cycles of $94^{\circ} \mathrm{C}$ for $1 \mathrm{~min}, 55^{\circ} \mathrm{C}$ (GSK-3 $\alpha$ and GSK-3 $\beta$ ) for $1 \mathrm{~min}, 72^{\circ} \mathrm{C}$ for $1 \mathrm{~min}$; and 1 cycle at $72^{\circ} \mathrm{C}$ for $2 \mathrm{~min}$.

Polymerase chain reaction products were separated on $2.0 \%$ (wt/vol) low melting agarose gels (Sigma) and isolated as previously described (Smith et al., 1998). Portions of the amplified products were digested for $2 \mathrm{hr}$ with DraI (GSK-3 $\alpha$ ) or BstXI (GSK-3 $\beta$ ). Undigested and digested PCR products, as well as PCR controls, were separated using $8 \%$ (wt/vol) polyacrylamide gel electrophoresis and visualized with ethidium bromide staining. Reverse transcription-PCR experiments were performed in triplicate with each primer set to ensure repeatability of results. In addition, purified PCR products were sequenced by cycle sequencing (ABI Prism, Perkin-Elmer) followed with product analysis using an Applied Biosystems Model 373A DNA Sequencer. Sequences obtained were compared with existing sequences in GenBank with the use of "BLAST" via the internet.

\section{Electrophoresis and Western Blot Analysis}

Fully grown GVI oocytes were cultured in HTF media containing $0.3 \%$ BSA for $2 \mathrm{hr}$. Oocytes that had undergone GVBD were selected and incubated for an additional 5 and $16 \mathrm{hr}$ for progression to MI and MII. Two hundred frozen cumulus cell-free, fully-grown GVI, $\mathrm{MI}$, and MII oocytes were thawed in $2 \times$ SDS-PAGE sample buffer [80 mM Tris-HCl $(\mathrm{pH}=6.8), 20 \%$ (vol/vol) glycerol, 4\% (wt/vol) SDS, 4\% (vol/vol) 2- $\beta$-mercaptoethanol, and $0.04 \%$ (wt/vol) bromophenol blue], vortexed and placed on ice for $15 \mathrm{~min}$. Following sonication on ice for $10 \mathrm{sec}$, samples were denatured at $90^{\circ} \mathrm{C}$ for $10 \mathrm{~min}$ and cooled on ice for $5 \mathrm{~min}$. Samples were stored at $-20^{\circ} \mathrm{C}$ until electrophoresis was performed.
Five micrograms of mouse brain and two hundred mouse oocytes total protein were added per lane and separated by one-dimensional SDS-PAGE (Laemmli, 1970). Gels were equilibrated in TBST [25 mM Tris-HCl (pH 7.8), $125 \mathrm{mM} \mathrm{NaCl}, 0.1 \%$ (vol/vol) Tween] and proteins transferred to Hybond-P PVDF membrane using a Semi-Dry Electrophoretic Transfer Cell (Bio-Rad Laboratories, Hercules, CA) according to the manufacturer's instructions. Blots were blocked in 5\% (wt/vol) nonfat milk in TBST at room temperature (RT) for $1 \mathrm{hr}$. Then, blots were incubated with anti-GSK-3 (diluted $1: 1000$, recognizes both $\alpha$ and $\beta$ isoforms, Upstate Biotechnology, Lake Placid, NY) antibody in TBST plus $5 \%$ nonfat milk at $4{ }^{\circ} \mathrm{C}$ overnight with gentle agitation. After completely washing, Blots were, incubated for $60 \mathrm{~min}$ at RT with agitation in an anti-rabbit horseradish peroxidase-conjugated IgG (diluted 1:10,000), washed three times in TBST and developed with ECL Plus reagents (Amersham Life Sciences, Buckinghamshire, UK) per manufacturer's instructions.

\section{Immunohistochemistry (IHC)}

Fixed, paraffin-embedded ovaries were sectioned at $5 \mu \mathrm{m}$ intervals, placed on superfrost-plus slides (Fisher Scientific, Itasca, IL), deparaffinized, placed in $100 \mathrm{mM}$ glycine buffer ( $\mathrm{pH}$ 3.65) and microwaved for $10 \mathrm{~min}$ for antigen retrieval (Shi et al., 1995). To reduce background signal, samples were placed in Tris buffered saline (TBS; $50 \mathrm{mM}$ Tris $\mathrm{pH} 7.6,150 \mathrm{mM} \mathrm{NaCl}$ ) containing $5.0 \%(\mathrm{vol} / \mathrm{vol})$ dimethyl sulfoxide and $0.2 \%$ (vol/vol) Tween-20 for $10 \mathrm{~min}$, rinsed in TBS and incubated for $10 \mathrm{~min}$ in TBS containing $0.3 \%$ (wt/vol) BSA, $1 \mathrm{mg} / \mathrm{ml}$ sodium azide, and $1.6 \%$ (vol/vol) normal goat serum (Vector Laboratories). In addition, endogenous avidin and biotin were neutralized with an avidin/ biotin blocking kit (Vector Laboratories). Slides were rinsed and incubated overnight with anti-GSK-3 (diluted 1:500) antibody at RT in a humidified chamber; slides were then rinsed, washed [TBS $+0.05 \%(\mathrm{vol} / \mathrm{vol})$ Tween-20], rinsed again and incubated with the biotinylated secondary antibody for $30 \mathrm{~min}$ at RT. After secondary antibody exposure, slides were quenched in $3.0 \%$ (vol/vol) $\mathrm{H}_{2} \mathrm{O}_{2}$ in $90 \%$ (vol/vol) methanol for $30 \mathrm{~min}$, then rinsed and incubated for $30 \mathrm{~min}$ in avidin-biotin conjugated to peroxidase (Vector Laboratories). After several rinses, sections were exposed to $0.025 \%$ (wt/vol) 3,3'-diaminobenzidine (DAB, Dojindo Labs-Wako Chemical, Richmond, VA), rinsed, counterstained with

TABLE 1. Primers Utilized for Polymerase Chain Reactions for Glycogen Synthase Kinase-3 (GSK-3) in Mouse Oocytes

\begin{tabular}{llcr}
\hline GSK-3 isoform & \multicolumn{1}{c}{ Primers $^{\text {a }}$ (sense and antisense) } & $\begin{array}{c}\text { Anticipated } \\
\text { amplified product (bp) }\end{array}$ & $\begin{array}{c}\text { Anticipated restriction } \\
\text { enzyme digest products (bp) }\end{array}$ \\
\hline GSK-3 $\alpha$ & 5' CTCACTAACTCTTCCTGAGG 3' & 417 & $235+182($ DraI) \\
GSK-3 3 & $5^{\prime}$ GGATGGTGTGAATCGACG 3' & 259 & $118+141(B s t$ XI) \\
& $5^{\prime}$ GGTGAATCGAGAAGAGCCAT 3' & & \\
\hline
\end{tabular}

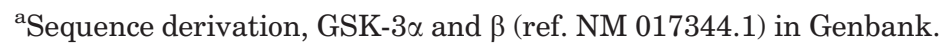


Mayer's hematoxylin (Sigma), dehydrated by three changes of ethanol, then three changes of xylene and mounted. Positive controls consisted of mouse heart. Negative controls included (1) elimination of the primary antibody (not shown) and (2) nonimmune rabbit serum (NIRS) in place of the primary antibody.

\section{Immunocytochemistry and Confocal Microscope Analysis}

In order to identify the effect of $\mathrm{LiCl}$ on microtubule assembly during oocyte maturation, in vitro-matured MII oocytes were collected and fixed in $2 \%$ (wt/vol) paraformaldehyde with $0.04 \%$ (vol/vol) Triton X-100. Oocytes were then blocked overnight with $0.3 \%$ (wt/vol) $\mathrm{BSA}$ in PBS at $4^{\circ} \mathrm{C}$, and incubated with a monoclonal anti- $\beta$ tubulin antibody at a 1:200 dilution for $1 \mathrm{hr}$ at $37^{\circ} \mathrm{C}$. After washing with $0.3 \%$ BSA plus $0.1 \%$ (vol $/ \mathrm{vol}$ ) Tween-20 in PBS, oocytes were incubated in the same wash buffer for $90 \mathrm{~min}$ at $37^{\circ} \mathrm{C}$. Samples were then reacted with anti-mouse Alexa 488-conjugated secondary antibody (Molecular Probes, Eugene, OR) at a 1:1,000 dilution for $1 \mathrm{hr}$ at $37^{\circ} \mathrm{C}$. Following washing, slides were incubated with $5 \mu \mathrm{g} / \mathrm{ml}$ propidium iodide (PI) in PBS containing $0.1 \%$ (wt/vol) BSA for $20 \mathrm{~min}$ at $37^{\circ} \mathrm{C}$. Slides were then mounted with $90 \%$ glycerol in PBS for fluorescence microscopic visualization with a Bio-Rad MRC-600 confocal scanning laser microscope.

\section{RESULTS}

\section{GSK-3 Transcript in Mouse Oocytes}

GSK-3 presence has never been reported in mammalian oocytes, therefore, we approached identification and characterization at the transcript and protein levels. Primers specific for rat brain GSK-3 $\alpha$ amplified an $\sim 417$ bp product from mouse brain cDNA produced by reverse transcription with either oligo-dT or genespecific primers (GSP; Fig. 1, lanes $\mathrm{H}$ and J). Amplified products from mouse brain contained the anticipated DraI digest sites that upon cleavage resulted in $\sim 235$ and 182 bp products (Fig. 1, lanes G and I). No amplification signals were detected in contamination control reactions (Fig. 1, lanes B-D). Complementary DNAs were produced by reverse transcription of fully-grown mouse oocyte RNA primed with oligo-dT and GSP. These two reverse transcription approaches were used because of GSK- $3 \alpha$ protein identification (discussed in following section) and concern that GSK- $3 \alpha$ transcript identification might be missed due to de-polyadenylation of transcript. However, PCR with primers for GSK- $3 \alpha$, using either oligo-dT or GSP-primed cDNA from fullygrown oocytes, showed no amplification product (Fig. 1, lanes $\mathrm{E}$ and F) indicating a lack of intact GSK- $3 \alpha$ transcript in fully-grown oocytes. Mouse oocyte cDNA produced by RT-PCR with primers specific for GSK-3 $\beta$ yielded approximately a 259 bp product (Fig. $2 \mathrm{~A}$, lane F) that contained the anticipated BstXI digest site (Fig. 2A, lane G). Control PCR reactions displayed no reagent contamination. The sequence of this product showed $97 \%$ similarity to rat brain GSK-3 $\beta$ (Fig. $2 \mathrm{~B}$ ).

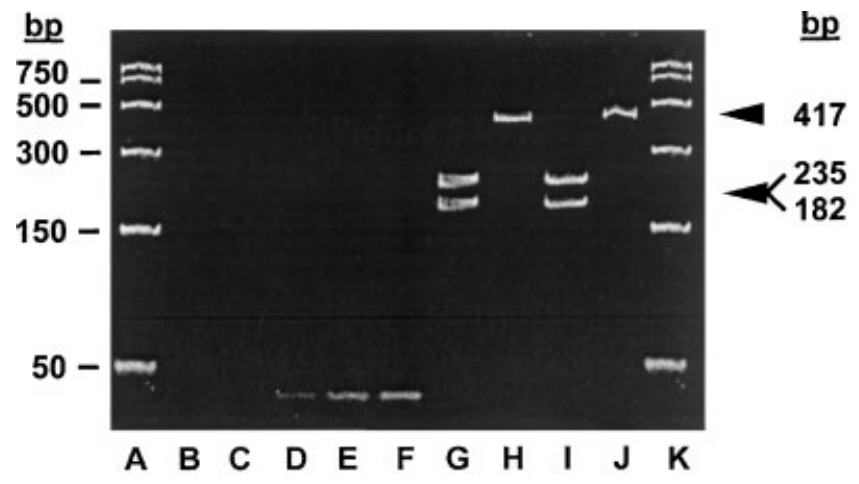

Fig. 1. Absence of glycogen synthase kinase- $3 \alpha$ (GSK- $3 \alpha$ ) mRNA in mouse oocytes. Polyacrylamide gel electrophoresis of PCR-amplified products of fully-grown GVI oocyte and brain cDNAs using primers designed from rat brain GSK- $3 \alpha$ sequence. Lanes $\mathbf{A}$ and $\mathbf{K}$, PCR markers; lane $\mathbf{B}$, no cDNA, no primers; lane $\mathbf{C}$, cDNA, no primers; lane $\mathbf{D}$, primers, no cDNA; lane $\mathbf{E}$, mouse oocyte cDNA produced using gene specific primers (GSP) for reverse transcription plus PCR primers; lane $\mathbf{F}$, mouse oocyte cDNA produced using oligo-dT primers (dT) for reverse transcription plus PCR primers; lane G, mouse brain cDNA produced using GSP for reverse transcription plus PCR primers followed by DraI digest; lane H, mouse brain cDNA produced using GSP for reverse transcription plus PCR primers; lane I, mouse brain cDNA produced using dT for reverse transcription plus PCR primers followed by $\mathrm{DraI}$ digest; lane J, mouse brain cDNA produced using $\mathrm{dT}$ for reverse transcription plus PCR primers.

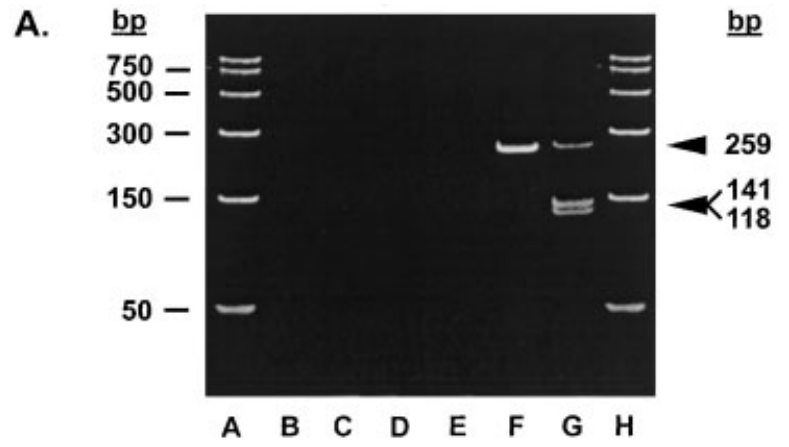

B.

\begin{tabular}{|c|c|c|c|}
\hline & AAG & $\mathrm{C}$ & $\mathrm{AC}$ \\
\hline 11 & TTTTGGTAGC & GCAGAGATAA & AGATGGCAGC \\
\hline 31 & AAGGTAACCA CAGTAGTGGC & AACTCCTGGC & AGGGTCC \\
\hline 21 & ACAGGCCACA GGAAGTCAGT & TATACAGACA & CGAAAGTGAT \\
\hline 61 & TGGAAATGGA TCATTTGGTG & TGGTATATCA & AGCCAAAC \\
\hline 0. & TGACT & & \\
\hline
\end{tabular}

N - Nucleotides different from rat brain GSK-3 $\beta$.

$97 \%$ similarity to rat brain GSK-3 $\beta$.

Fig. 2. Identification of mouse oocyte GSK- $3 \beta$ mRNA by RT-PCR/ polyacrylamide gel electrophoresis and cDNA sequencing. A: PAGE of PCR-amplified products of fully-grown GVI oocytes cDNA using primers designed from rat brain GSK-3 $\beta$. Lanes $\mathbf{A}$ and $\mathbf{H}$, PCR markers; lane B, no cDNA, no primers; lane $\mathbf{C}$, cDNA, no primers; lane $\mathbf{D}$, primers, no cDNA; lane $\mathbf{E}$, mouse oocyte total RNA and primers; lane $\mathbf{F}$, mouse oocyte cDNA and primers; lane $\mathbf{G}$, mouse oocyte cDNA and primers followed by BstXI digest. B: Sequence of mouse oocyte GSK-3 $\beta$ PCR-amplified product, which showed 97\% similarity to rat brain GSK-3 $\beta$. Underlined nucleotides are dissimilar to rat brain GSK-3ß. 


\section{GSK-3 Protein in Mouse Oocytes}

To further confirm the presence of GSK-3 in mouse oocytes, Western blot analyses were performed on isolated denuded fully-grown oocytes. Both $\alpha$ and $\beta$ isoforms of GSK-3 were identified at 51 and $46 \mathrm{kDa}$, respectively, within the positive control tissue, mouse brain, and mouse oocytes (Fig. 3). To further investigate the presence and intra-oocyte location of GSK-3, immunohistochemistry experiments were performed on ovarian tissue removed from pre-pubertal (11- and 15-days-old) and PMSG-stimulated adult mice. For nonspecific signal controls, GSK-3 antibody was replaced with nonimmune rabbit serum (NIRS). These controls displayed negligible staining in mouse prepubertal and PMSG-stimulated adult (not shown) ovaries, as well as heart (Fig. 4). In addition, mouse heart was used as positive control tissue and showed intense, diffuse cytoplasmic staining of the myofibril cytoplasm. Ovaries of prepubertal mice 11 and 15 days of age predominantly contain static and growing oocytes within primordial, primary and secondary follicles (Fig. 4). These oocytes contain GSK-3, which displays diffuse staining throughout the cytoplasm and a marked absence within the nucleus. Fully-grown oocytes in late preantral and antral follicles from PMSG-stimulated adult ovaries show diffuse cytoplasmic staining of GSK-3, absence in the nucleus and a concentration in close proximity to the oolemma.

\section{GSK-3 and Oocyte Meiosis}

In order to investigate the functional importance of GSK-3 in mammalian oocytes we utilized the IMPase/ GSK-3 inhibitor, LiCl. Culturing GVI oocytes in increasing doses of $\mathrm{LiCl}$ for $16 \mathrm{hr}$ had no significant effect on oocyte viability, as assessed by degeneration, GVBD, or MII development in comparison to no-treatment or $\mathrm{KCl}$ controls (Table 2). At the light microscope level, morphological appearance of in vitro-matured oocytes treated with $20 \mathrm{mM} \mathrm{LiCl}$ was similar to control and $20 \mathrm{mM} \mathrm{KCl}$ treatments. However, MII oocytes matured

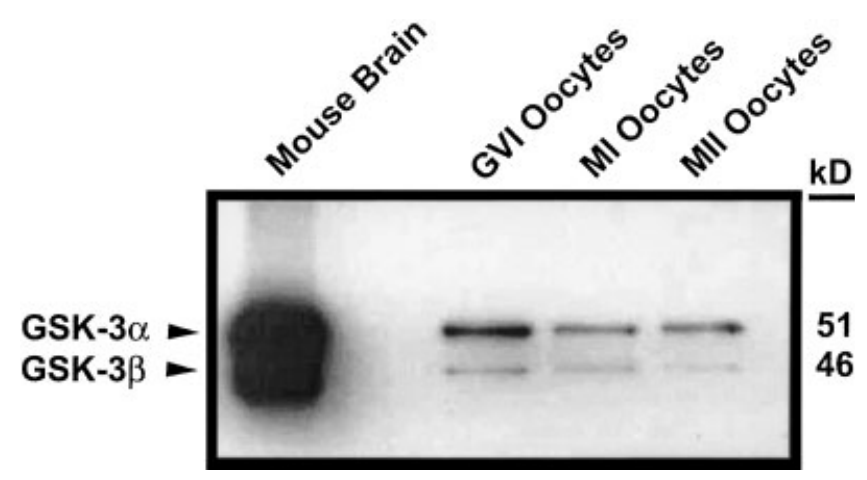

Fig. 3. Immunoblot analysis of GSK-3 $\alpha$ and $\beta$ in fully-grown GVI, MI, and MII mouse oocytes. Approximately $5 \mu \mathrm{g}$ of mouse brain (positive controls for GSK- $3 \alpha$ and $\beta$ ), or 200-cumulus cell-free oocyte total protein were loaded per lane. The polyclonal antibody used recognized both GSK- $3 \alpha$ and $\beta$ at $\sim 51$ and $46 \mathrm{kDa}$, respectively, in positive control tissues. Mouse oocytes contained GSK- $3 \alpha$ and GSK-3 $\beta$. in the presence of $20 \mathrm{mM} \mathrm{LiCl}$ had reduced microtubule polymerization, abnormal MII spindle formation and aberrant homologue segregation (Fig. 5). Because lithium can inhibit both GSK-3 and IMPase, we used the specific IMPase inhibitor-L690,330 (Atack et al., 1993; Klein and Melton, 1996) in a similar experimental protocol to determine if this influence of $\mathrm{LiCl}$ on homologue segregation was due to inhibition of GSK-3 or IMPase. Oocyte viability (not shown), GVBD, MII development, and oocyte activation (Table 3) were not significantly different between treatments. In addition, morphological appearance of oocytes, as visualized with light microscopy, was normal and similar between treatments (data not shown). All MII oocytes in each treatment group were assessed for normal (Fig. 6A) or abnormal (Fig. 6B-F) homologue segregation. MII oocytes cultured in LiCl had significantly higher incidence of abnormal homologue segregation (39.8\%; $P<0.01)$ compared to control media $(4.2 \%)$, $\mathrm{KCl}$ (4.6\%), and L690,330 (5.9\%) treatments (Fig. 7).

\section{DISCUSSION}

GSK-3 was first identified as the kinase that phosphorylates and inactivates glycogen synthase, which is the rate-limiting enzyme in glycogen synthesis (Embi et al., 1980; Rylatt et al., 1980; Hemmings et al., 1982). Subsequently GSK-3 was found to be identical to factor $\mathrm{A}\left(\mathrm{F}_{\mathrm{A}}\right)$ that was known to activate PP1 through phosphorylation of I2 (Vandenheede et al., 1980). Molecular cloning revealed the existence of two highly-related proteins termed GSK- $3 \alpha$ and GSK-3 $\beta$ with molecular masses of 51 and $46 \mathrm{kDa}$, respectively (Hughes et al., 1992). We have addressed the identification of mouse oocyte GSK-3 from both transcript and protein levels. Initially, using RT-PCR with oligo-dT-primed reverse transcription we identified GSK- $3 \beta$, but not GSK- $3 \alpha$, transcripts in fully-grown mouse oocytes. These experiments were followed by repeated Western blot analyses of fully-grown mouse oocyte proteins with an antibody that recognizes both $\alpha$ and $\beta$ forms of GSK-3. A 51-kDa protein was recognized, corresponding to GSK-3 $\alpha$, in addition to the $46-\mathrm{kDa}$ protein corresponding to GSK- $\beta$. Because de-polyadenylation of transcripts has been reported previously in the oocyte (Bachvarova and Paynton, 1988), we speculated that we might have missed the GSK-3 $\alpha$ transcript with the use of oligo-dT primed reverse transcription. These experiments were repeated with gene-specific primers for reverse transcription. Even though this scenario resulted in amplification of GSK-3 $\alpha$ in control tissue we were unable to amplify a product from oocytes. In addition, mRNA within the oocyte samples was present, and intact, as supported by the ability to serve as a template for GSK$\beta$. Thus, we have concluded that within the mouse oocyte GSK- $3 \alpha$ is transcribed, translated, and its mRNA is subsequently degraded, whereas GSK-3 $\beta$ is transcribed, translated, and its transcript remains stable. This raises the question of importance of oocyte-derived GSK-3 $\beta$ transcript in early embryogenesis. Conversely, it stimulates the questioning of if/when GSK-3 $\alpha$ gene 

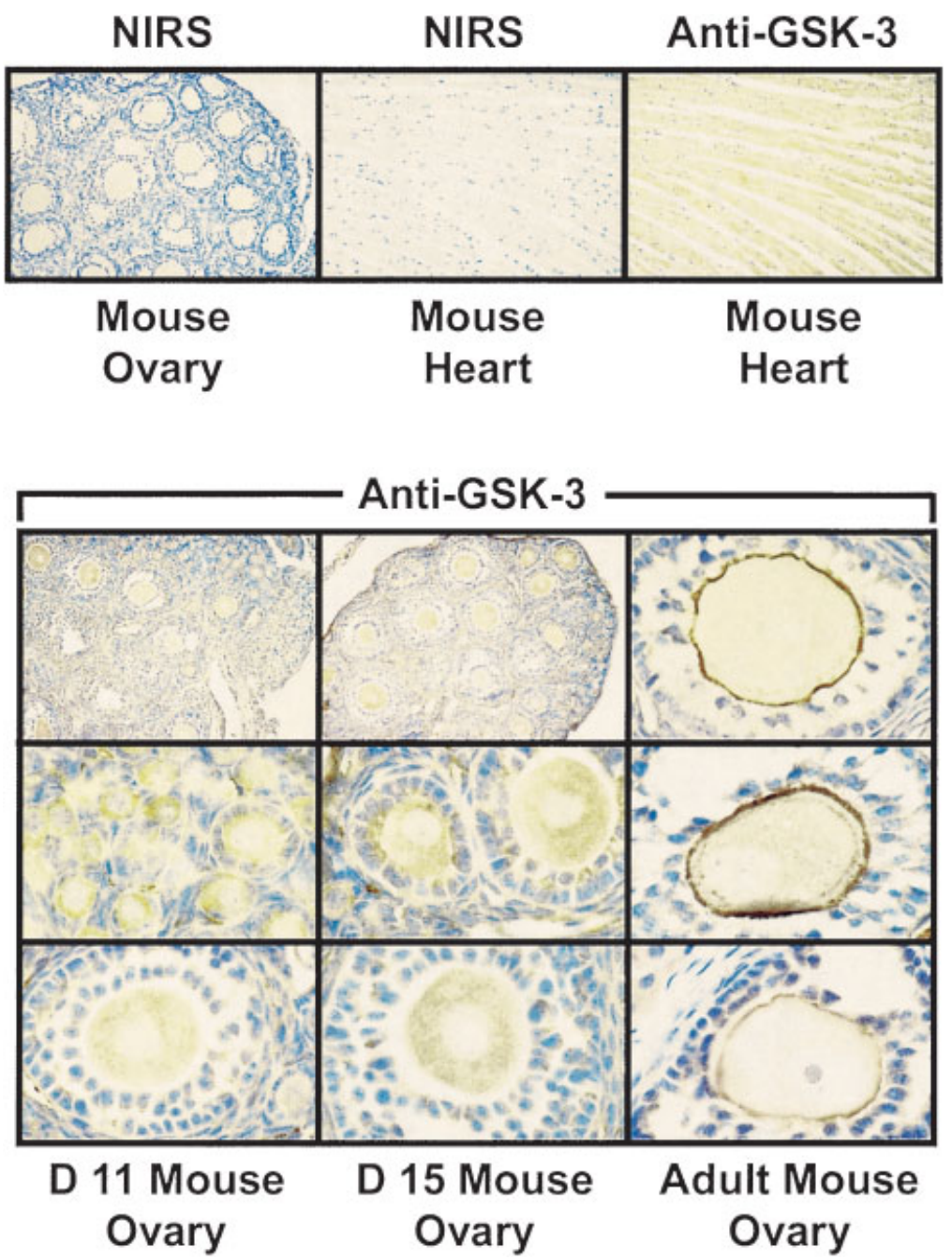

Fig. 4. Representative immunohistochemical localization of GSK-3 in mouse oocytes during prepubertal ovarian development around the time of age-related acquisition of meiotic competence and following adult PMSG-stimulation. Nonimmune rabbit serum (NIRS) replacing the primary antibody showed negligible background staining in mouse ovaries and heart. Polyclonal antibodies, which recognizes both GSK-

$3 \alpha$ and $\beta$, displayed reactivity in the cytoplasm of mouse myofibrils (positive control tissue). Oocyte GSK-3 was detectable in the cytoplasm at 11 and 15 days of age, when the majority of oocytes are GVBincompetent and beginning to acquire meiotic competence, respectively. In adult PMSG-stimulated ovaries cytoplasmic GSK-3 is present with a pronounced intensity in close proximity to the oolemma.

expression is turned-on during preimplantation embryo development. Both of these questions need to be addressed in the future.

We also asked the question where, within the oocyte, is GSK-3 located with respect to developmental competence. The diffuse cytoplasmic staining of GSK-3 in oocytes of all sizes and contained in all stages of follicles present on days 11 and 15 is quite different from the

Fig. 5. Representative immunocytochemical identification of microtubule polymerization, spindle formation, and chromation localization in MII oocytes matured in $\mathrm{KCl}(\mathbf{a}$; insert) or $\mathrm{LiCl}(\mathbf{A}-\mathbf{D})$. Green and red fluorescence indicates $\beta$-tubulin and chromatin staining, respectively. All MII oocytes, independent of treatment, were processed at the same time, under identical conditions, and assessed with scanning laser microscopy. Oocytes matured in $\mathrm{KCl}$ (a, insert) and $\mathrm{LiCl}(\mathrm{A}, \mathrm{B})$ were visualized under identical fluorescent intensities. The same MII oocytes mature in $\mathrm{LiCl}(\mathrm{A}, \mathrm{B})$ were further assessed with increased fluorescent intensity (C and D, respectively) in attempts to identify microtubule polymerization.
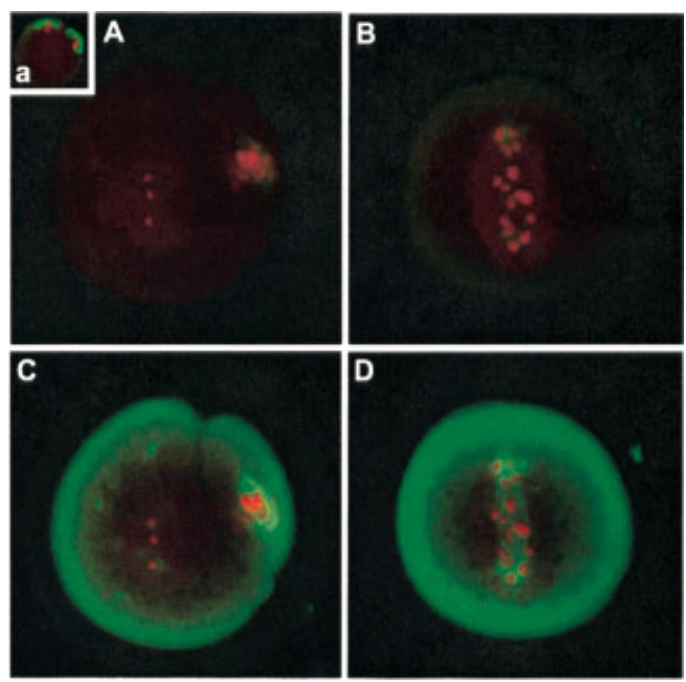
TABLE 2. Survival and In Vitro Maturation of Mouse Oocytes After $16 \mathrm{hr}$ Exposure to Increasing Doses of the GSK-3/Inositol Monophosphatase (IMPase) Inhibitor, Lithium Chloride (LiCl)

\begin{tabular}{lcccc}
\hline Treatment & $\mathrm{N}$ & $\begin{array}{c}\text { Degenerate } \\
(\%)\end{array}$ & $\begin{array}{c}\text { Germinal vesicle } \\
\text { breakdown }(\mathrm{GVBD})(\%)^{\mathrm{a}}\end{array}$ & $\begin{array}{c}\text { Metaphase II (MII) } \\
\text { development }(\%)^{\mathrm{a}}\end{array}$ \\
\hline Control (HTF-H) & 57 & $5(9)$ & $48(92)$ & $39(75)$ \\
KCl $(5 \mathrm{mM})$ & 51 & $4(8)$ & $46(98)$ & $41(87)$ \\
$(10 \mathrm{mM})$ & 48 & $3(6)$ & $45(100)$ & $40(89)$ \\
$(20 \mathrm{mM})$ & 55 & $4(7)$ & $47(92)$ & $39(76)$ \\
$\mathrm{LiCl}(5 \mathrm{mM})$ & 45 & $2(4)$ & $41(95)$ & $32(75)$ \\
$(10 \mathrm{mM})$ & 49 & $4(8)$ & $45(100)$ & $49(87)$ \\
$(20 \mathrm{mM})$ & 64 & $3(5)$ & $61(100)$ & $49)$ \\
\hline
\end{tabular}

HTF-H, human tubal fluid with HEPES.

${ }^{a}$ Rates of GVBD and MII development were calculated based on viable oocytes.

predominant staining in close proximity to the oolemma seen in similarly-sized oocytes and follicular stages in adult mice primed with PMSG. Thus, this intracellular trafficking of GSK-3 within oocytes is not related to oocyte size or follicular stage but, more importantly, related to animal age and/or exogenous hormone stimulation. This would also indicate that this peri-oolemma location of GSK-3 is not requisite for development of meiotic competence because no such staining was found in oocytes from 15-day-old mice when oocytes are beginning to gain meiotic competence (Schultz and Wassarman, 1977). This translocation of GSK-3 may be a component of cytoplasmic oocyte maturation occurring following completion of the oocyte growth phase.

In somatic and neuronal cells $\mathrm{LiCl}$ is commonly used to investigate the role of GSK-3 in cell function (Stambolic et al., 1996; Lovestone et al., 1999; Manji et al., 1999; Ohteki et al., 2000). It is important to note that LiCl, at levels utilized in past (Klein and Melton, 1996; Choi and Sung, 2000) and the current study, inhibits both GSK-3 and IMPase. While we fully acknowledge the limitations of this approach we have attempted to address this specificity issue by inclusion of the specific IMPase inhibitor, L690,330 (Atack et al., 1993; Klein and Melton, 1996). While increasing doses of $\mathrm{LiCl}$ had no recognizable influence of oocyte viability, development, or morphology; it had striking effects on microtubule polymerization, spindle formation, and homologue segregation. This was first visualized in immunocytochemistry studies where MII oocytes matured in control media, $20 \mathrm{mM} \mathrm{KCl}$, or $20 \mathrm{mM} \mathrm{LiCl}$ were processed side-by-side in an identical fashion for identification of spindle formation and chromatin segregation. Both control-(not shown) and KCl-treated MII oocytes (Fig. 5, insert) displayed normal microtubule polymerization and homologue separation and segregation. Using laser intensities determined from controls and $\mathrm{KCl}$ treatment groups we initially observed homologue segregation problems and very little signal for $\beta$-tubulin in oocyte matured in the presence of $\mathrm{LiCl}$ (Fig. 5A,B). Increasing laser intensity enabled visualization of some microtubule polymerization within $\mathrm{LiCl}$ treated oocytes, yet this polymerization resulted in abnormal spindle formation. Recall, these oocytes had undergone cytokinesis and morphologically resembled MII oocytes. Thus, the question remains: is $\mathrm{LiCl}$ compromising formation and function of MI, MII, or both metaphase spindles? While this question remains to be answered experiments have focused on quantitation of LiCl-induced homologue separation and segregation problems and whether this effect is due to GSK-3 or IMPase inhibition.

In control and $\mathrm{KCl}$-supplemented media incidence of abnormal homologue segregation was $\sim 5 \%$, which is similar to previously reported values (Sun et al., 2001). Maturation of oocytes in $\mathrm{LiCl}$ induces a significant increase in homologue segregation problems in comparison to controls. Interestingly, the specific IMPase inhibitor, L690,330, did not phenocopy the effects of $\mathrm{LiCl}$ on mouse oocyte homologue segregation during the first meiotic division. This would suggest that aneuploidy problems seen following LiCl-treatment are due to GSK-3 inhibition and not IMPase inhibition. These results are similar to those generated in determining

TABLE 3. Survival and In Vitro Maturation of Mouse Oocytes in the Presence of the (GSK-3)/IMPase Inhibitor, LiCl, and the Specific IMPase Inhibitor, L690,330

\begin{tabular}{lrccc}
\hline Treatment & N & $\begin{array}{c}\text { Germinal vesicle } \\
\text { breakdown }\left(\text { GVBD }(\%)^{\text {a }}\right.\end{array}$ & $\begin{array}{c}\text { Metaphase II (MII) } \\
\text { development }(\%)^{\mathrm{a}}\end{array}$ & $\begin{array}{c}\text { Oocyte } \\
\text { activation }(\%)^{\mathrm{a}}\end{array}$ \\
\hline Control (HTF-H) & 93 & $81(96)$ & $72(86)$ & $1(1)$ \\
$\mathrm{KCl}(20 \mathrm{mM})$ & 84 & $77(95)$ & $69(85)$ & $0(0)$ \\
$\mathrm{LiCl}(20 \mathrm{mM})$ & 108 & $106(99)$ & $98(92)$ & $0(0)$ \\
$\mathrm{L} 690,330(20 \mu \mathrm{M})$ & 108 & $100(96)$ & $88(85)$ & $1(1)$ \\
\hline
\end{tabular}

HTF-H, human tubal fluid with HEPES.

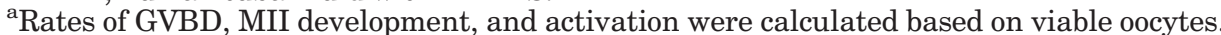




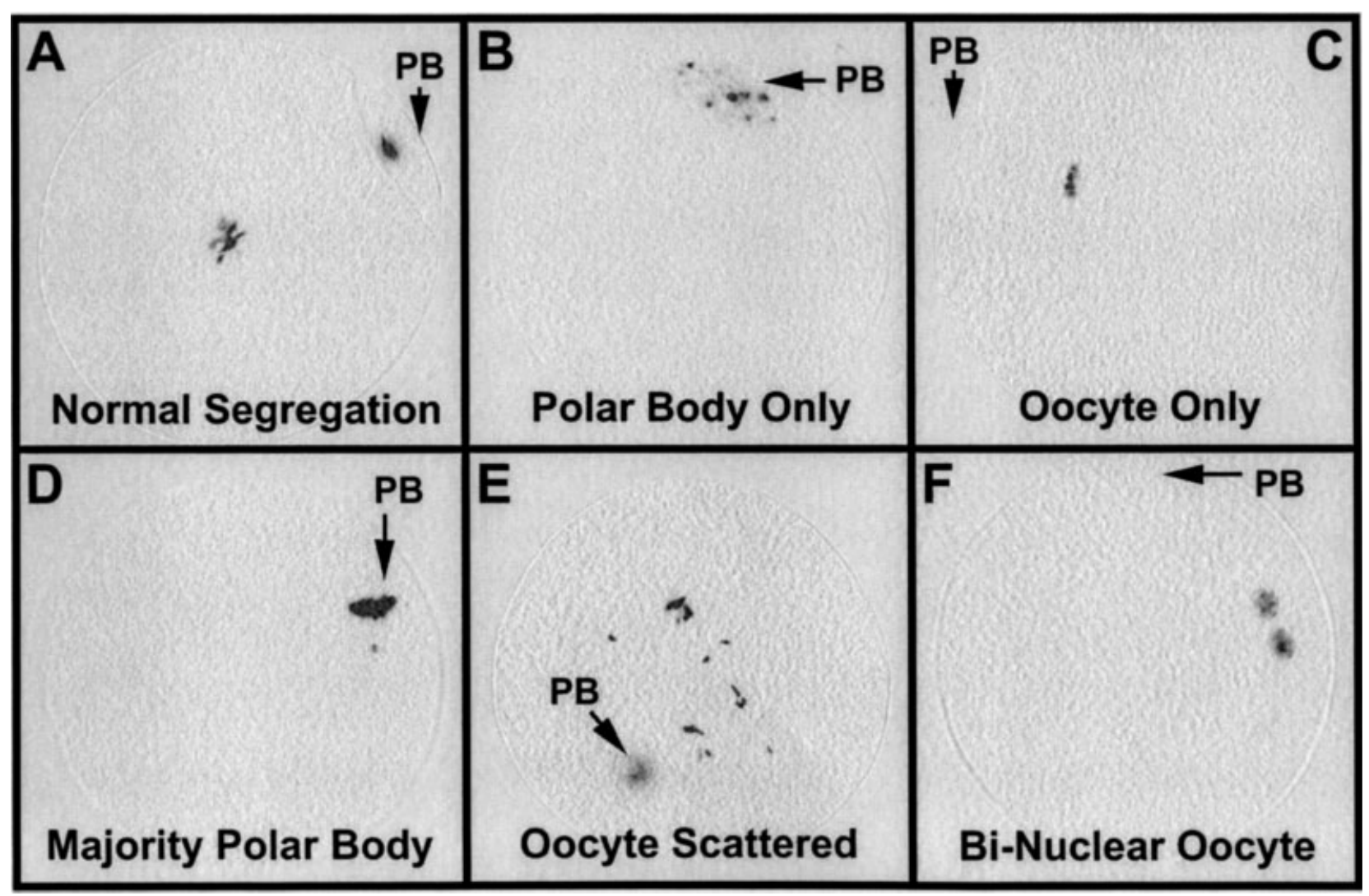

Fig. 6. Representative MII oocytes with various categories of homologue segregation patterns. In vitromature MII oocytes in all treatment regimens (control media, $20 \mathrm{mM} \mathrm{KCl}, 20 \mathrm{mM} \mathrm{LiCl}$, or $20 \mu \mathrm{M} \mathrm{L690,330)}$ were assessed, blind to treatment, and categorized as having normal (A) or abnormal (B-F) homologue segregation. Quantitative results are presented in Figure 7.

the mechanism by which $\mathrm{LiCl}$ induces dorsal-ventral axis formation aberrations in invertebrate embryogenesis (Kao et al., 1986; Klein and Melton, 1996; Rogers and Varmuza, 1996). How GSK-3 is involved with oocyte

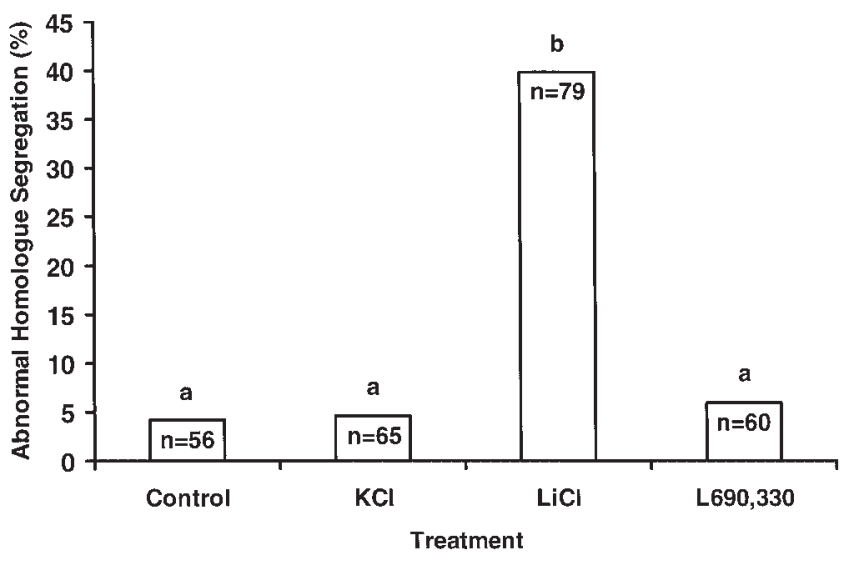

Fig. 7. Percentage of MII oocytes matured in presence of control media, $\mathrm{KCl}, \mathrm{LiCl}$, or L690,330 with abnormal homologue segregation. Following $16 \mathrm{hr}$ of in vitro maturation, in various treatment regimens, morphologically normal MII oocytes were stained with Hoechst 3342 and visualized, blind to treatment, with fluorescent microscopy. $\mathrm{n}=$ number of MII oocytes assessed in each treatment. Columns with different letters are significantly different, $P<0.01$. meiotic homologue segregation remains to be determined. One mechanism may involve GSK-3 regulation of microtubule-associated protein phosphorylation, normal microtubule polymerization, and normal meiotic spindle formation. GSK-3 $\beta$ has been demonstrated to have important functional roles in mitotic spindle orientation in early Caenorhabditis elegans embryos (Schlesinger et al., 1999) and dorsal-ventral axis formation in Xenopus (Dominguez et al., 1995) and zebrafish (Sumoy et al., 1999) embryos. In neuronal cells GSK-3 influences microtubule polymerization by regulating phosphorylation of microtubule-associated proteins such as tau (Hong et al., 1997; Lovestone et al., 1999), oncoprotein 18, or stathmin (Moreno and Avila, 1998), microtubule-associated protein 1 and 2 (Salinas, 1999; Sanchez et al., 2000). GSK-3 inhibition reduces phosphorylation of microtubule-associated proteins and results in abnormal microtubule polymerization. These microtubule-associated proteins have yet to be identified in mammalian oocytes. Whether this mode of mediation explains the influence of LiCl-induced inhibition of GSK-3 and aberrant homologue segregation is a current area of investigation. On the other hand, GSK-3 may regulate the phosphorylation of chromatid associated proteins that direct normal homologue separation and segregation. Recently, cohesin, securins, 
and separase have been described and implicated in the regulation of chromatid separation during mitosis (Uhlmann, 2001), as well as homologue and sister centromere separation during the first and second meiotic divisions, respectively (Buonomo et al., 2000). The phosphorylated state of cohesin and securins dictate their integrity and/or activity (Sanchez et al., 1999; Uhlmann et al., 2000) and the kinases and phosphatases regulating this reversible phosphorylation remain to be fully identified. Whether GSK-3 regulates homologue segregation during the first oocyte meiotic division through one of these, or through another pathway, remains to be determined.

\section{ACKNOWLEDGMENTS}

The authors thank Dr. Carrie Cosola-Smith for critically reviewing the manuscript. This work was supported by NIH Grant HD35125-01A1 (G.D.S.).

\section{REFERENCES}

Atack JR, Cook SM, Watt AP, Fletcher SR, Ragan CI. 1993. In vitro and in vivo inhibition of inositolmonophosphatase by the bisphosphonate L-690,330. J Neurochem 60:652-658.

Bachvarova R, Paynton B. 1988. Gene expression during growth and meiosis maturation of mouse oocytes. Prog Clin Biol Res 267:6785.

Bagger PV, Byskov AG, Christiansen MD, Bang L, Mortensen L. 1993. Lithium stimulates the first meiosis division in mouse oocytes. Acta Obstet Gynecol Scand 72:514-519.

Berridge MJ, Downes CP, Hanley MR. 1989. Neural and developmental actions of lithium: A unifying hypothesis. Cell 59:411-419.

Boyle WJ, Smeal T, Defize LH, Angel P, Woodgett JR, Karin M, Hunter T. 1991. Activation of protein kinase C decreases phosphorylation of c-Jun at sites that negatively regulate its DNA-binding activity. Cell 64:573-584.

Buonomo SBC, Clyne RK, Fuchs J, Loidl J, Uhlmann F, Nasmyth K. 2000. Disjunction of homologous chromosomes in meiosis I depends on proteolytic cleavage of the meiotic cohesin Rec8 by separin. Cell 103:387-398.

Choi WS, Sung CK. 2000. Effects of lithium and insulin on glycogen synthesis in L6 myocytes: Additive effects on inactivation of glycogen synthase kinase-3. Biochim Biophys Acta 1475:225-230.

Cook D, Fry MJ, Hughes K, Sumathipala R, Woodgett JR, Dale TC. 1996. Wingless inactivates glycogen synthase kinase-3 via an intracellular signaling pathway which involves a protein kinase C. EMBO J 15:4526-4536

Coticchio G, Fleming S. 1998. Inhibition of phosphoinositide metabolism or chelation of intercellular calcium blocks FSH-induced but not spontaneous meiotic resumption in mouse oocytes. Dev Biol 203: 201-209.

Dominguez I, Itoh K, Sokol SY. 1995. Role of glycogen synthase kinase 3 beta as a negative regulator of dorsovental axis formation in Xenopus embryos. Proc Natl Sci USA 92:8498-8502.

Embi N, Rylatt BD, Cohen P. 1980. Glycogen synthase kinase-3 from rabbit skeletal muscle. Separation from cyclic-AMP-dependent protein kinase and phosphorylase kinase. Eur J Bioch 107:519527.

Fiol CJ, Williams JS, Chou CH, Wang QM, Roach PJ, Andrisani OM. 1994. A secondary phosphorylation of CREB341 at Ser129 is required for the cAMP-mediated control of gene expression. A role for glycogen synthase kinase-3 in the control of gene expression. J Biol Chem 269:32187-32193.

Gavin AC, Schorderet-Slatkine S. 1988. The interaction of lithium with forskolin-inhibited meiotic maturation of denuded mouse oocytes. Exp Cell Res 179:298-302.

Hallcher LM, Sherman WR. 1980. The effects of lithium ion and other agents on the activity of the myo-inositol-1-phosphatase from bovine brain. J Biol Chem 255:10896-10901.
Heikinheimo O, Lanzendorf SE, Baka SG, Gibbons WE. 1995. Cell cycle genes-c-mos and cyclin-B1 are expressed in a specific pattern in human oocytes and preimplantation embryos. Hum Reprod 10:699_ 707.

Hemmings BA, Yellowlees D, Kernohan JC, Cohen P. 1981. Purification of glycogen synthase kinase 3 from rabbit skeletal muscle. Copurification with the activating factor (FA) of the (Mg-ATP) dependent protein phosphatase. Eur J Bioch 119:443-451.

Hemmings BA, Resink TJ, Cohen P. 1982. Reconstitution of a MgATP-dependent protein phosphatase and its activation through a phosphorylation mechanism. FEBS Lett 150:319-324.

Hong M, Chen DC, Klein PS, Lee VM. 1997. Lithium reduces tau phosphorylation by inhibition of glycogen synthase kinase-3. J Biol Chem 272:25326-25332.

Hughes K, Pulverer BJ, Theocharous P, Woodgett JR. 1992. Baculovirus-mediated expression and characterization of rat glycogen synthase kinase-3 beta, the mammalian homologue of the Drosophila melanogaster zeste-white 3sgg homeotic gene product. Eur J Bioch 203:305-311.

Kao KR, Masui Y, Elinson RP. 1986. Lithium-induced despecification of pattern in Xenopus laevis embryos. Nature 322:371-373.

Klein PS, Melton DA. 1996. A molecular mechanism for the effect of lithium on development. Proc Natl Sci USA 93:8455-8459.

Laemmli UK. 1970. Cleavage of structural proteins during the assembly of the head of bacteriophage T4. Nature 227:680- 685

Lovestone S, Davis DR, Webster MT, Kaech S, Brion JP, Matus A, Anderton BH. 1999. Lithium reduces tau phosphorylation: Effects in living cells and in neurons at therapeutic concentrations. Biol Psychiatry 45:995-1003.

Manji HK, Moore GJ, Chen G. 1999. Lithium at 50: Have the neuroprotective affects of this unique cation been overlooked? Biol Psychiatry 46:929-940.

Moreno FJ, Avila J. 1998. Phosphorylation of stathmin modulates its function as a microtubule depolymerizing factor. Mol Cell Biochem 183:201-209.

Ohteki T, Parsons M, Zakarian A, Jones RG, Nguyen LT, Woodgett JR, Ohashi PS. 2000. Negative regulation of T cell proliferation and interleukin 2 production by the serine threonine kinase GSK-3. J Exp Med 192:99-104.

Pesty A, Lefevre B, Kubiak J, Geraud G, Tesarik J, Maro B. 1994. Mouse oocytes maturation is effected by lithium via the polyphosphoinositol metabolism and the microtubule network. Mol Reprod Dev 38:187-199.

Phiel CJ, Klein PS. 2001. Molecular targets of lithium action. Annu Rev Pharmacol Toxicol 41:789-813.

Plyte SE, Hughes K, Nikolakaki E, Pulverer B, Woodgett JR. 1992. Glycogen synthase kinase-3: Functions in oncogenesis and development. Biochem Biophys Acta 1114:147-162.

Quinn P, Kerin J, Warnes G. 1985. Improved pregnancy rate in human in vitro fertilization with the use of a medium based on the composition of human tubal fluid. Fertil Steril 44:493-498.

Rogers I, Varmuza S. 1996. Epigenetic alterations brought about by lithium treatment disrupt mouse embryo development. Mol Reprod Dev 45:163-170.

Rylatt DB, Aitken A, Bilham T, Condon GD, Embi N, Cohen P. 1980 Glycogen synthase from rabbit skeletal muscle. Amino acid sequence at the sites phosphorylated by glycogen synthase kinase-3, and extension of the N-terminal sequence containing the site phosphorylated by phosphorylase kinase. Eur J Bioch 107:529-537.

Sakanaka C, Sun TQ, Williams LT. 2000. New steps in the Wnt/betacatenin signal transduction pathway. Recent Prog Horm Res 55: 225-236.

Salinas PC. 1999. Wnt factors in axonal remodelling and synaptogenesis. Biochem Soc Symp 65:101-109.

Sanchez Y, Bachant J, Wang H, Hu F, Liu D, Tetzlaff M, Elledge SJ. 1999. Control of the DNA damage checkpoint by chkl and rad53 protein kinase through distinct mechanism. Science 286:1166-1171.

Sanchez C, Perez M, Avila J. 2000. GSK3beta-mediated phosphorylation of the microtubule-associated protein 2C (MAP2C) prevents microtubule bundling. Eur J Cell Biol 79:252-260.

Schlesinger A, Shelton CA, Maloof JN, Meneghini M, Bowerman B. 1999. Wnt pathway components orient a mitotic spindle in the early 
Caenorhabditis elegans embryo without requiring gene transcription in the responding cell. Genes Dev 13:2028-2038.

Schultz RM, Wassarman PM. 1977. Biochemical studies of mammalian oogenesis: Protein synthesis during oocyte growth and meiotic maturation in the mouse. J Cell Sci 24:167-194.

Shi S-R, Gu J, Kalra K, Chen T, Cote R, Taylor CR. 1995. Antigen retrieval technique: A novel approach to immunohistochemistry on routinely processed tissue sections. Cell Vision 2:6-22.

Smith GD, Wolf DP, Trautman KC, da Cruz e Silva EF, Greengard P, Vijayaraghavan S. 1996. Primate sperm contain protein phosphatase 1, a biochemical mediator of motility. Biol Reprod 54:719727.

Smith GD, Sadhu A, Mathies S, Wolf DP. 1998. Characterization of protein phosphatases in mouse oocytes. Dev Biol 204:537549 .

Smith GD, Wolf DP, Trautman KC, Vijayaraghavan S. 1999. Motility potential of macaque epididymal sperm: The role of protein phosphatase and glycogen synthase kinase-3 activities. J Andrology 20: $47-53$.

Stambolic V, Ruel L, Woodgett JR. 1996. Lithium inhibits glycogen synthase kinase-3 activity and mimics wingless signalling in intact cells. Current Biol 6:1664-1668.
Sumoy L, Kiefer J, Kimelman D. 1999. Conservation of intracellular Wnt signaling components in dorsal-ventral axis formation in zebrafish. Dev Genes Evol 209:48-58.

Sun F, Yin H, Eichenlaub-Ritter U. 2001. Differential chromosome behaviour in mammalian oocytes exposed to the tranquilizer diazepam in vitro. Mutagenesis 16:407-417.

Uhlmann F. 2001. Secured cutting: Controlling separase at the metaphase to anaphase transition. EMBO Rep 2:487-492.

Uhlmann F, Wernic D, Poupart MA, Koonin EV, Nasmyth K. 2000. Cleavage of cohesin by the $\mathrm{CD}$ clan protease separin triggers anaphase in yeast. Cell 103:375-386.

Vandenheede JR, Yang SD, Goris J, Merlevede W. 1980. ATP $\times$ Mgdependent protein phosphatase from rabbit skeletal muscle. II. Purification of the activating factor and its characterization as a bifunctional protein also displaying synthase kinase activity. J Biol Chem 255:11768-11774.

Vijayaraghavan S, Mohan J, Gray H, Khatra B, Carr DW. 2000. A role for phosphorylation of glycogen synthase kinase-3alpha in bovine sperm motility regulation. Biol Reprod 62:16471654.

Woodgett JR. 1990. Molecular cloning and expression of glycogen synthase kinase-3/factor A. EMBO J 9:2431-2438. 